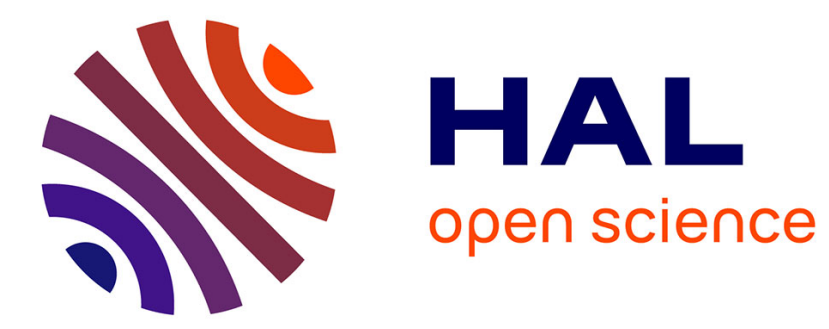

\title{
THICK FLUID INTERFACE MODELING
}

Roger Prud'Homme, Renée Gatignol

\section{To cite this version:}

Roger Prud'Homme, Renée Gatignol. THICK FLUID INTERFACE MODELING. ISTP13, Jul 2002,

Victoria, Canada. hal-03041578

\section{HAL Id: hal-03041578 \\ https://hal.science/hal-03041578}

Submitted on 5 Dec 2020

HAL is a multi-disciplinary open access archive for the deposit and dissemination of scientific research documents, whether they are published or not. The documents may come from teaching and research institutions in France or abroad, or from public or private research centers.
L'archive ouverte pluridisciplinaire HAL, est destinée au dépôt et à la diffusion de documents scientifiques de niveau recherche, publiés ou non, émanant des établissements d'enseignement et de recherche français ou étrangers, des laboratoires publics ou privés. 


\section{THICK FLUID INTERFACE MODELING}

\section{Roger Prud'homme and Renée Gatignol}

LMM, Université Pierre et Marie Curie/CNRS - 4 Place Jussieu - 75252 Paris Cedex 05

\begin{abstract}
Basic concepts of interface and interfacial layer are first introduced. Orthogonal curvilinear coordinate analysis, used to study interfacial zones depending of time, is presented. Classical 3D and 2D thermodynamical relations are reminded and second gradient formulation is introduced. Then general balance laws are written and examples are given to illustrate the purpose.
\end{abstract}

\section{INTRODUCTION}

Interfaces are often compared with geometrical surfaces. But these surfaces have internal physical properties and must be considered as material surfaces. They are the seat of multiple exchanges with their surrounding, i.e. the bulks in contact with them. Thermodynamical properties and balance laws of interfaces are not always simple to obtain. It is often necessary to work with several scales of analysis. At microscopic scale, 2D interfaces become 3D interfacial layers, where thermodynamical relations and balance equations must be written. A review is presented in our book [1].

Many authors were interested by interfacial modeling. Interfacial fluid layers endowed with internal capillarity were studied in particular by Casal [2,3], Germain [4], Gouin [5], Seppecher [6] and Gatignol [7]. Concept of interface extended to stretched flames were considered by Klimov [8], Sivashinski [9], Clavin and Joulin [10], Prud'homme [11]. For the concept of an "interface" with internal energy per unit aera, one can cite Delhaye [12], Scriven [13], Slattery [14]. Rocard [15] gave a statistical approach and Casal, Gouin, Germain, Seppecher a macroscopic approach. Discussion about interfacial velocities were driven by Landau and Lifschitz [16], Bedeaux, Albano and Mazur [17], Napolitano [18], Prosperetti [19] and, for interfaces with surface mass, by Ghez $[20,21]$, Prud'homme [22]. In relation with the concept of an "interfacial layer", Ishii [23], Gogosov [24], Sanfeld and Steinchen [25] utilize true quantities, and on the contrary, Landau and Lifschitz, Meinhold and Heerlein [26] excess quantities. The concept of dividing surface was utilized by Gibbs [27], Slattery [28], Defay et al. [29]. Many authors have established interfacial balance equations, but not always with the desirable strictness. One try here to point out some crucial problems and suggest solutions.

\section{INTERFACE AND INTERFACIAL LAYER}

The concept of an interface is relative. Some material surface seams very thin at a given scale and appear to be thick at a smaller one (Fig. 1).
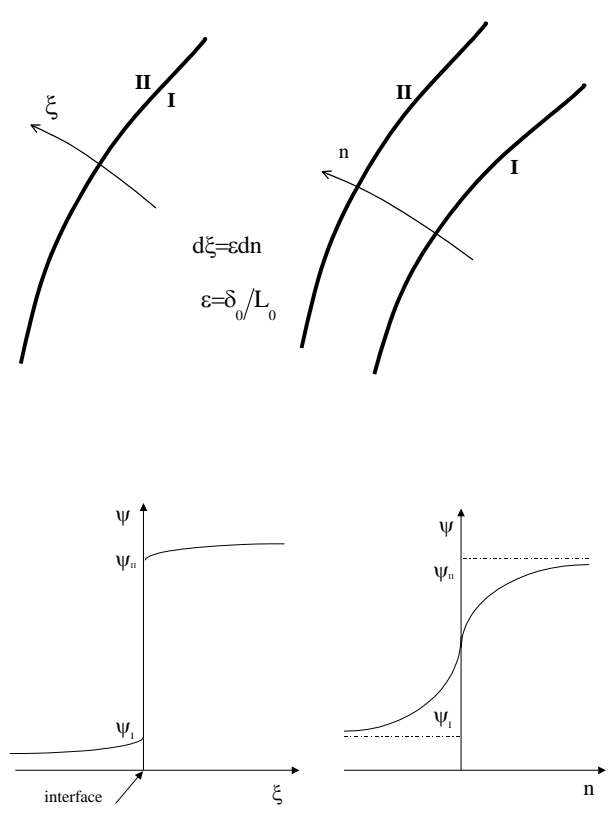

a) Interface (at the scale $\mathrm{L}_{0}$ )

b) Interfacial layer (at the scale $\delta_{0}$ )

Fig. 1

As examples of interface, one can mention various systems as capillary surfaces, miscible interfaces, some flames, and so on, all systems whose properties verify the same type of balance equations at a convenient scale.

One consider here only fluid interfaces, i.e., themselves fluid, without rigidity, and located between bulk fluids.

Modeling of such interfaces means establishing equations of material surfaces $(2 D$ balance equations) and closing the obtained system by constitutive relations.

2D interfacial properties can be deduced from 3D analysis, by integration across the interfacial layer. Then, interfacial quantities $\psi_{\mathrm{a}}$ and $\psi_{\mathrm{S}}$ are deduced from local 3D properties by integration between the boundaries of the interfacial layer. It gets

$\psi_{\mathrm{a}}=\rho_{\mathrm{a}} \psi_{\mathrm{S}}=\int_{\xi_{\mathrm{I}}}^{\xi_{\mathrm{II}}} \rho \psi \mathrm{d} \xi$

with the surface density 
$\rho_{\mathrm{a}}=\int_{\xi_{\mathrm{I}}}^{\xi_{\mathrm{II}}} \rho \mathrm{d} \xi$

Applying (1) to the fluid velocity $\vec{V}$, it gets

$\rho_{\mathrm{a}} \overrightarrow{\mathrm{V}}_{\mathrm{S}}=\int_{\xi_{\mathrm{I}}}^{\xi_{\mathrm{II}}} \rho \overrightarrow{\mathrm{V}} \mathrm{d} \xi$

To calculate the integrals of the right hand member it is sometimes necessary to apply an asymptotic expansion method and to use a new coordinate $\mathrm{n}$ at smaller scale than $\xi$ with $\mathrm{d} \xi=\varepsilon \mathrm{dn}$

$\psi_{\mathrm{a}}=\int_{\xi_{\mathrm{I}}}^{\xi_{\mathrm{II}}} \rho \psi \mathrm{d} \xi=\varepsilon \int_{-\infty}^{+\infty} \rho \psi \mathrm{dn}$

\section{ORTHOGONAL CURVILINEAR COORDINATES}

It is generally convenient to consider the interfacial layer as a stratified structure. On each surface of this structure we suppose that the value of a characteristic parameter q (local density, temperature or concentration) is constant. Use of a system of orthogonal curvilinear coordinates can be made, and each surface of the stratified structure, on which the characteristic parameter $q$ remains constant, can be seen as a coordinate surface $\mathrm{S}_{3}\left(\mathrm{x}_{3}, \mathrm{t}\right)$ or $\mathrm{S}_{3}$ - obtained for a given value of $\mathrm{x}_{3}$ at time t.

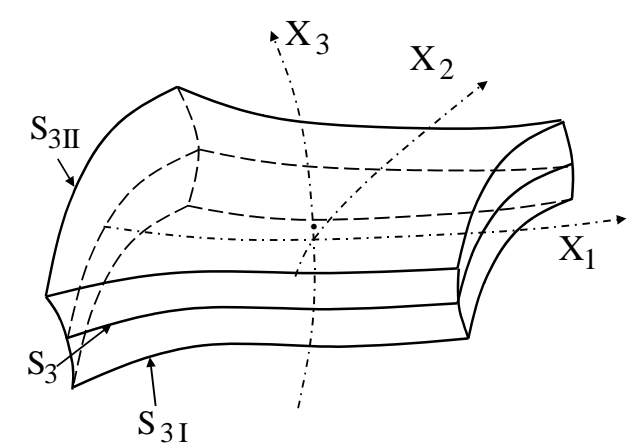

Fig. 2. Curvilinear orthogonal coordinates; coordinate surfaces.

Let us consider the following moving curvilinear system

$\mathrm{x}=\mathrm{x}\left(\mathrm{x}_{1}, \mathrm{x}_{2}, \mathrm{x}_{3}, \mathrm{t}\right)$

$y=y\left(x_{1}, x_{2}, x_{3}, t\right)$, or: $\vec{x}=\vec{x}\left(x_{1}, x_{2}, x_{3}, t\right)$

$\mathrm{z}=\mathrm{z}\left(\mathrm{x}_{1}, \mathrm{x}_{2}, \mathrm{x}_{3}, \mathrm{t}\right)$

$\mathrm{x}, \mathrm{y}$ and $\mathrm{z}$ being the Cartesian coordinates in an orthonormal basis $(\vec{i}, \vec{j}, \vec{k}), x_{1}, x_{2}$ and $x_{3}$ the curvilinear coordinates and $\mathrm{t}$ the time.
We call $\vec{h}_{\mathrm{i}}$, the vector of components $\left(\mathrm{x}, \mathrm{i}_{\mathrm{i}}, \mathrm{y}, \mathrm{i}_{\mathrm{i}}, \mathrm{z}, \mathrm{i}_{\mathrm{i}}\right)$. For the orthogonal curvilinear system of coordinates, the vectors $\overrightarrow{\mathrm{h}}_{\mathrm{i}}, \overrightarrow{\mathrm{h}}_{\mathrm{j}}(\mathrm{i} \neq \mathrm{j})$ are orthogonal at any point. Dividing by the norm $\left|\vec{h}_{\mathrm{i}}\right|=\mathrm{h}_{\mathrm{i}}$, we obtain the normalized vector $\overrightarrow{\mathrm{e}}_{\mathrm{i}}=\overrightarrow{\mathrm{h}}_{\mathrm{i}} / \mathrm{h}_{\mathrm{i}}$ and we define the curvilinear abscissa by $d X_{i}=h_{i} d_{i}$ (Fig. 2). The mean curvature of surface $S_{3}$ is then

$\frac{1}{\delta \mathrm{S}_{3}} \frac{\partial\left(\delta \mathrm{S}_{3}\right)}{\partial \mathrm{X}_{3}}=\vec{\nabla} \cdot \overrightarrow{\mathrm{e}}_{3}=\frac{1}{\mathrm{~h}_{3}}\left(\frac{\mathrm{h}_{1,3}}{\mathrm{~h}_{1}}+\frac{\mathrm{h}_{2,3}}{\mathrm{~h}_{2}}\right)$

Projection operators can be defined [1] (for instance one define $\overrightarrow{\overrightarrow{\mathrm{I}}}_{\perp}=\overrightarrow{\mathrm{e}}_{3} \overrightarrow{\mathrm{e}}_{3}$, and $\overrightarrow{\overrightarrow{\mathrm{I}}} / /=\overrightarrow{\overrightarrow{\mathrm{I}}}-\overrightarrow{\mathrm{e}}_{3} \overrightarrow{\mathrm{e}}_{3}$ ), and a local velocity $\overrightarrow{\mathrm{W}}$ inside the interfacial layer is introduced (Fig. 3) by the formula

$\overrightarrow{\mathrm{W}}=\overrightarrow{\mathrm{V}}_{/ /}+\mathrm{w} \overrightarrow{\mathrm{e}}_{3}$,

with: $\overrightarrow{\mathrm{V}}_{/ /}=\overrightarrow{\mathrm{I}}_{/ /} \cdot \overrightarrow{\mathrm{V}}, \overrightarrow{\mathrm{w}}=\frac{\partial \overrightarrow{\mathrm{x}}}{\partial \mathrm{t}} \equiv \overrightarrow{\mathrm{h}}_{\mathrm{t}}, \quad \mathrm{w}=\overrightarrow{\mathrm{e}}_{3} \cdot \overrightarrow{\mathrm{h}}_{\mathrm{t}}=\overrightarrow{\mathrm{I}}_{\perp} \cdot \overrightarrow{\mathrm{h}}_{\mathrm{t}}$.

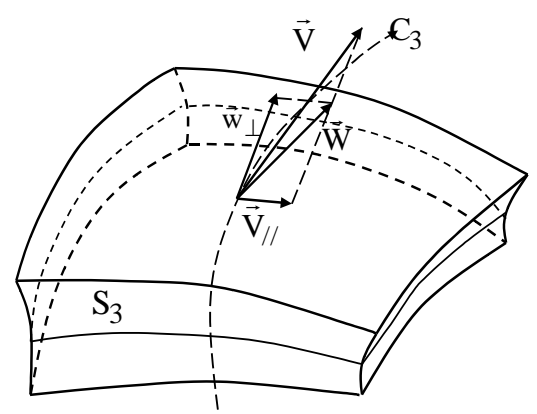

Fig. 3. Velocities inside the interface layer

The stretch of a surface $S_{3}$ moving locally at velocity $\overrightarrow{\mathrm{W}}$ is then

$\frac{1}{\delta \mathrm{S}_{3}} \frac{\mathrm{d}_{\overrightarrow{\mathrm{w}}}\left(\delta \mathrm{S}_{3}\right)}{\mathrm{dt}}=\vec{\nabla} \cdot \overrightarrow{\mathrm{W}}-\vec{\nabla} \cdot \overrightarrow{\mathrm{W}}=\vec{\nabla} /, \overrightarrow{\mathrm{W}}$

with $\vec{\nabla}_{\perp}=\overrightarrow{\overrightarrow{\mathrm{I}}} \cdot \vec{\perp}, \vec{\nabla}_{/ /}=\overrightarrow{\overrightarrow{\mathrm{I}}}_{/ /} \cdot \vec{\nabla}$.

Quantities defined by (6), (7) and (8) are very important for the interface description because they have physical meaning.

\section{THERMODYNAMICAL RELATIONS}

For the bulk and the interfacial layer in the case of a classical fluid mixture, the internal energy $E$ of a given volume of fluid is an order one homogeneous 
function of its entropy $\mathrm{S}$, its volume $v$ and the masses of species $m_{j}$, which are extensive quantities. This gives, for the unit mass, the Euler, Gibbs and Gibbs-Duhem well known relations:

$\mathrm{e}=\mathrm{Ts}-\mathrm{p} v+\sum_{\mathrm{j}=1}^{\mathrm{N}} \mathrm{g}^{\mathrm{j}} \mathrm{Y}^{\mathrm{j}}, \mathrm{de}=\mathrm{Tds}-\mathrm{pd} v+\sum_{\mathrm{j}=1}^{\mathrm{N}} \mathrm{g}^{\mathrm{j}} \mathrm{d} \mathrm{Y}^{\mathrm{j}}$,

$0=s d T-v d p+\sum_{j=1}^{N} Y^{j} d g^{j}$

For the 2D interface, usual thermodynamical relations read

$\mathrm{e}_{\mathrm{S}}=\mathrm{T}_{\mathrm{S}} \mathrm{S}_{\mathrm{S}}+\sigma / \rho_{\mathrm{a}}+\sum_{j=1}^{\mathrm{N}} \mathrm{g}_{\mathrm{S}}^{\mathrm{j}} \mathrm{Y}_{\mathrm{S}}^{\mathrm{j}}, \mathrm{de}_{\mathrm{S}}=\mathrm{T}_{\mathrm{S}} \mathrm{ds}_{\mathrm{S}}+\sigma \mathrm{d}\left(1 / \rho_{\mathrm{a}}\right)+\sum_{\mathrm{j}=1}^{\mathrm{N}} \mathrm{g}_{\mathrm{S}}^{\mathrm{j}} \mathrm{dY} \mathrm{Y}_{\mathrm{S}}^{\mathrm{j}}$,

$0={ }_{S} \mathrm{dT}_{S}+\left(1 / \rho_{\mathrm{a}}\right) \mathrm{d} \sigma+\sum_{j=1}^{N} Y_{S}^{j} \mathrm{dg}_{S}^{\mathrm{j}}$

In the case of 3D interfacial fluid layers with internal capillarity, and taking a one component fluid for simplicity, internal energy $E$ of the stratified layer - a volume with a small thickness $\Delta \xi$ around a coordinate surface - is an order one homogeneous function of quantities $\mathrm{S}, v$, the mass $\mathrm{m}$, and of a complementary extensive variable $S$, which is homogeneous to an area, but is not equal to the area of the part of $S_{3}$ contained in the considered volume.

One has $S=\int_{V} \frac{1}{v}\left|\frac{\mathrm{d} v}{\mathrm{~d} \xi}\right| \mathrm{d} \mathcal{V}$, and the internal energy per unit mass becomes e $=\mathrm{e}\left(\mathrm{s}, v,\left|\frac{\mathrm{d} v}{\mathrm{~d} \xi}\right|\right)$.

One can write

$$
\begin{aligned}
& \mathrm{e}=\mathrm{Ts}-\mathrm{p} v+\Lambda\left|\frac{\mathrm{d} v}{\mathrm{~d} \xi}\right|+\mathrm{g}, \mathrm{de}=\mathrm{Tds}-\mathrm{pd} v+\Lambda \mathrm{d}\left|\frac{\mathrm{d} v}{\mathrm{~d} \xi}\right|, \\
& 0=\mathrm{sdT}-v \mathrm{dp}+\left|\frac{\mathrm{d} v}{\mathrm{~d} \xi}\right| \mathrm{d} \Lambda+\mathrm{dg}
\end{aligned}
$$

More usually, one write $[1,6]$

$$
\mathrm{e}=\mathrm{e}\left(\mathrm{s}, \rho,|\vec{\nabla} \rho|^{2}\right), \mathrm{de}=\mathrm{Tds}-\mathrm{pd}\left(\frac{1}{\mathrm{p}}\right)+\lambda \vec{\nabla} \rho \cdot \mathrm{d}(\vec{\nabla} \rho)
$$

\section{GENERAL BALANCE LAW}

The local form of the balance equation for any property, whose volumetric value is denoted by $\rho \psi$, is
$\frac{\mathrm{d}_{\overrightarrow{\mathrm{W}}}(\rho \psi)}{\mathrm{dt}}+\rho \psi \vec{\nabla} \cdot \overrightarrow{\mathrm{W}}+\vec{\nabla} \cdot[\overrightarrow{\mathrm{J}}+\rho \psi(\overrightarrow{\mathrm{V}}-\overrightarrow{\mathrm{W}})]=\rho \phi$

where velocity $\overrightarrow{\mathrm{W}}$ is defined by (7) and where $\mathrm{d}_{\overrightarrow{\mathrm{w}}} / \mathrm{dt}$ stands for the convective derivative associated to $\vec{W}$. An integration of the two sides of (13) across the interfacial layer leads to the balance law for the 2D interface

$\left.\frac{\mathrm{d}_{\overrightarrow{\mathrm{w}}_{\mathrm{s}}}\left(\rho_{\mathrm{a}} \psi_{\mathrm{S}}\right)}{\mathrm{dt}}+\rho_{\mathrm{a}} \psi_{\mathrm{S}} \vec{\nabla}_{\mathrm{s}} \cdot \overrightarrow{\mathrm{W}}_{\mathrm{S}}+\left[\left(\overrightarrow{\mathrm{J}}+\rho \psi\left(\overrightarrow{\mathrm{V}}-\overrightarrow{\mathrm{W}}_{\mathrm{S}}\right)\right) \vec{\xi}\right]\right]$
$+\vec{\nabla}_{\mathrm{S}} \cdot \overrightarrow{\mathrm{J}}_{\mathrm{a} / /}=\rho_{\mathrm{a}} \phi_{\mathrm{S}}$

with definitions (1) to (3) for the interfacial variables, $\vec{W}_{S}$ being defined by (3) with $\vec{W}$ in place of $\vec{V}$, and with the flux $\overrightarrow{J_{a}}=\int_{\xi_{I}}^{\xi_{I I}}\left[\vec{J}+\rho \psi\left(\vec{V}-\vec{W}_{S}\right)\right] d \xi$. The average velocities are shown on Fig. 4.

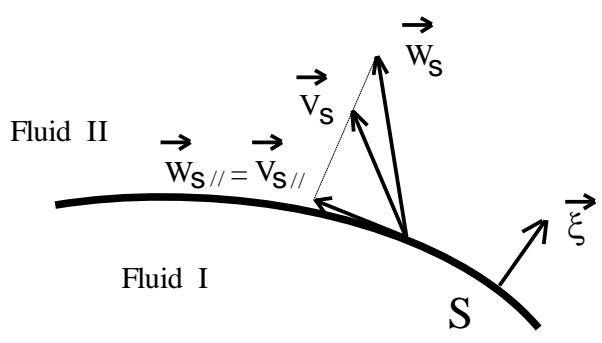

Fig. 4. The different velocities on the 2D interface S.

General surface balance law (14) can be applied to masses of species and to total mass. An alternative form of (14) may then be deduced

$\rho_{\mathrm{a}} \frac{\mathrm{d}_{\mathrm{S}} \psi_{\mathrm{S}}}{\mathrm{dt}}+\llbracket \mathrm{J}_{\perp}+\dot{\mathrm{m}}\left(\psi-\psi_{\mathrm{S}}\right) \rrbracket+\vec{\nabla}_{\mathrm{S}} \cdot \overrightarrow{\mathbf{J}}_{\mathrm{a} / /}=\rho_{\mathrm{a}} \phi_{\mathrm{S}}$

and may be applied to momentum, total energy, internal energy and entropy. An interfacial ClausiusDuhem inequality is then written which first member is a sum of products of terms of zero, one and two tensorial order terms.

\section{INTERFACIAL CONSTITUTIVE RELATIONS}

\section{D closure relations}

Then, the two-dimensional surface entropy production $\Delta_{\mathrm{a}}$ is such that the surface dissipation

$\mathrm{T}_{\mathrm{S}} \Delta_{\mathrm{a}}$ has the symbolic form: 
$\mathrm{T}_{\mathrm{s}} \Delta_{\mathrm{a}}=\sum_{\alpha=1}^{\mathrm{m}} \mathcal{A}_{\mathrm{s}}^{\alpha} \mathcal{J}_{\mathrm{s}}^{\alpha} \geq 0$

Each product corresponds to an irreversible phenomena, and $\mathcal{A}_{\mathrm{S}}^{\alpha}$ and $\mathcal{J}_{\mathrm{S}}^{\alpha}$ represent the generalized forces and fluxes.

This result suggests applying the general principles of Irreversible Thermodynamics [30] and writing linear closure relations between generalized forces and fluxes of same tensorial order

$\mathcal{J}_{\mathrm{S}}^{\alpha}=\sum_{\beta=1}^{\mathrm{m}} \mathrm{L}_{\mathrm{S}}^{\alpha \beta} \mathcal{A}_{\mathrm{S}}^{\alpha}$

This method is usually applied to classical problems related to capillarity at equilibrium (where $\mathrm{p}_{\mathrm{II}}-\mathrm{p}_{\mathrm{I}}=-\sigma \vec{\nabla} \cdot \vec{\xi}$ ), or out of equilibrium (where $\left.-\llbracket \overrightarrow{\vec{T}} \rrbracket \cdot \vec{\xi}+\llbracket p \rrbracket \vec{\xi}-\vec{\nabla}_{\mathrm{S}} \sigma+\sigma(\vec{\nabla} \cdot \vec{\xi}) \vec{\xi}=0\right)$, and it is possible to introduce surface viscosities [28]. Marangoni effect, Bénard-Marangoni instability [31], surface heat transfer, evaporation-condensation, near-equilibrium surface chemical reactions, may be studied with this method. There are important simplifications for interfaces without mass [1]. Coefficients $L_{S}^{\alpha \beta}$ are generally deduced from molecular theory and experimental measurements. The previous method is no more valid for material surfaces far from equilibrium, but constitutive relations can be found in the literature in specific cases, as for vapor recoil [32, 33, 34], adsorptiondesorption, and surface chemical reaction with nonlinear kinetics.

\section{D closure relations}

Some situations can not be directly studied using surface equations, and a preliminary study of the interfacial layer behavior is necessary.

This is the case for some wetting problems [35] where fluid layers with capillarity must be considered as 3D interfacial layers, and the second gradient method utilized $[1,2,6]$. For such a fluid inside the interfacial layer and assuming that it is without dissipation

$\overrightarrow{\vec{\Sigma}}=-\mathrm{p}_{*} \overrightarrow{\overrightarrow{\mathrm{I}}}-\lambda \vec{\nabla} \rho \vec{\nabla} \rho$

(In simple cases it is possible to connect surface tension $\sigma$ to capillarity coefficient $\lambda$, writing [6] $\left.\sigma=\int_{\xi_{1}}^{\xi_{I I}}-\mathrm{p}_{*}(\xi) \mathrm{d} \xi \cong \int_{\xi_{1}}^{\xi_{\mathrm{II}}} \lambda|\vec{\nabla} \rho|^{2} \mathrm{~d} \xi\right)$.

For some generalized interfaces, as premixed flames with high activation energy [8-11], shock waves and relaxation zones behind shock waves [36, 37], interfacial layer instability between two miscible fluids
[38], interfacial layer instability in a pure heated supercritical fluid [39], some shear layers [40], it is possible to deduce surface properties. But this results from a detailed study of the interfacial layer, which obeys generally to linearized (heat and species diffusion, viscosity) or non-linear (chemical kinetics) classical constitutive relations. For premixed flames with high activation energy, the obtained combustion velocity is a linear function [10] of surface stretch $\vec{\nabla}_{\mathrm{S}} \cdot \overrightarrow{\mathrm{W}}_{\mathrm{S}}$ as defined by (8), but in strongly turbulent flows the stretch dependence becomes non-linear. In the case of interfacial layer between two miscible fluids, or in the shear layers, the stability analysis shows an influence of the interfacial layer on the growing curve $\left(\omega_{i}\right.$ in function of $k$ ) similar to the one of surface tension on Rayleigh and Kelvin-Helmholtz instability growing curve (Fig. 5). This suggests inserting of an effective surface tension.

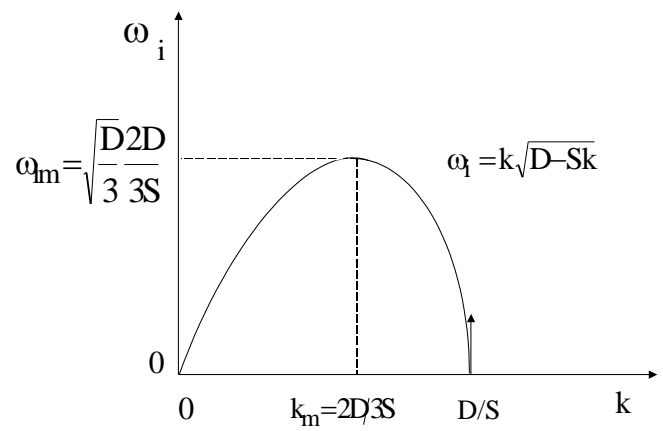

Fig. 5. Amplification factor for two semi infinite superposed fluids, without gravity in inviscid fluids with surface tension:,

$$
\mathrm{S}=\frac{\sigma}{\rho_{1}+\rho_{2}} \mathrm{D}=\frac{\rho_{1} \rho_{2}\left(\mathrm{U}_{1}-\mathrm{U}_{2}\right)^{2}}{\left(\rho_{1}+\rho_{2}\right)^{2}}
$$

\section{OTHER RELEVANT QUESTIONS}

Interfacial zone appeared as a stratified region. This is a relatively comfortable situation, where the balance equation for area can be directly deduced from interfacial kinematics written in curvilinear coordinates. Indeed, the material derivative of $\Sigma$, the density of area per unit volume of the structured layer (see (8)) reads

$$
\begin{aligned}
& \frac{1}{\Sigma} \frac{\mathrm{d}_{\overrightarrow{\mathrm{w}}} \Sigma}{\mathrm{dt}}=\frac{1}{\delta \mathrm{S}_{3}} \frac{\mathrm{d}_{\overrightarrow{\mathrm{w}}} \delta \mathrm{S}_{3}}{\mathrm{dt}}-\frac{1}{\delta \mathcal{V}} \frac{\mathrm{d}_{\overrightarrow{\mathrm{w}}} \delta \mathcal{V}}{\mathrm{dt}} \\
& =\vec{\nabla}_{/ /} \cdot \overrightarrow{\mathrm{W}}-\vec{\nabla} \cdot \overrightarrow{\mathrm{W}}=-\vec{\nabla} \cdot \overrightarrow{\mathrm{W}}
\end{aligned}
$$

This equation (in an other form) is utilized by Candel \& Poinsot [41] for flames. In turbulent burning flows, average quantities are introduced and source terms appear on right-hand side of (19). 
An other case is the one of two-phase mixtures. Lhuillier, Morel \& Delhaye [42] introduce a distribution function $\delta_{\text {I }}$ for the interfacial area $\Sigma$ per unit volume of the mixture. Writing a balance equation for $\delta_{\mathrm{I}}$, a source term $\gamma$ appears, which vanishes if applied to our simple stratified interfacial layer.

In this paper, interfacial modeling of fluid was presented in such a manner that $2 \mathrm{D}$ description result generally from 3D analysis. The 2D description often leads to discontinuities, and it is difficult to solve numerically this type of problem. Then, some authors try to obtain continuous equations even in discontinuous situations. Phase field models have been described for solidification of alloys. The interface is considered as a transition region where averaged local quantities weighted by the liquid and solid volume fractions are introduced. At macroscopic scale, we find an enthalpy method [43] whereas at smaller case, balance equations are deduced by minimization of free energy in functional analysis [44]. Jamet et al. [45] use a second gradient method with an artificially thickened interface, and Jamet and Petitjeans [46] apply phase field models to interfaces of diffusion.

\section{NOMENCLATURE}

$\mathcal{A}_{\mathrm{S}}^{\alpha}$ interfacial generalized force

$\mathcal{J}_{\mathrm{S}}^{\alpha}$ interfacial generalized flux

$k$ wave number

$\mathrm{L}_{0}$ hydrodynamic scale

$\mathrm{L}_{\mathrm{s}}^{\alpha \beta}$ interfacial phenomenological coefficient

$\mathrm{n}$ normal coordinate at small scale

$\mathrm{p}_{*}$ interfacial pressure

q physical parameter

$\mathrm{S}_{3}$ coordinate surface

$t$ time

$\overrightarrow{\vec{T}}$ but

bulk viscous stress tensor

$U$ velocity

$\overrightarrow{\mathrm{V}}$ local fluid velocity

$\overrightarrow{\mathrm{W}}$ velocity of the surface $\mathrm{S}_{3}$

$x, y, z$ Cartesian coordinates

$\mathrm{x}_{1}, \mathrm{x}_{2}, \mathrm{x}_{3}$ curvilinear coordinates

$\overrightarrow{\mathrm{X}}$ position of a point

$\delta_{0}$ interfacial thickness

$\varepsilon$ small parameter $\varepsilon=\delta_{0} / \mathrm{L}_{0}<<1$

$\psi$ any property per unit mass

$\xi$ normal coordinate at any scale

$\vec{\xi}$ unit normal to the interface

$\rho$ fluid density $\sigma$ surface tension

$\overrightarrow{\vec{\Sigma}}$ bulk stress tensor

$\omega_{\text {i }}$ amplification factor

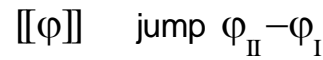

\section{Subscripts}

1,2 both sides for superposed fluids

I, II lower and upper limits of an interfacial layer

,i space derivative $\partial / \partial x_{i}$

//, S parallel to the interface

$\perp$ normal to the interface

\section{REFERENCES}

1. Gatignol, R. \& Prud'homme, R. (2001): Mechanical and thermodynamical modeling of fluid interfaces, Series of Advances in Mathematics for Applied Sciences-Vol. 58, World Scientific, Singapore.

2. Casal, P. (1961): "La capillarité interne", Cahier du Groupe Français de Rhéologie, CNRS, VI, No 3, 31-37.

3. Casal, P. (1972): "La théorie du second gradient et la capillarité", C. R. Acad. Sci. Paris, 274, Série A, 1571-1574.

4. Germain, P. (1973): "La méthode des puissances virtuelles en mécanique des milieux continus", $J$. Mécanique, 12, p. 235-274.

5. Casal, P. \& Gouin, H. (1988): "A representation of liquid-vapor interfaces by using fluids of second grade", Ann. Phys., Colloque 2, supplément au n 3 , 13, 3-12.

6. Seppecher, P. (1987): Etude d'une modélisation des zones capillaires fluides: Interfaces et lignes de contact, Thèse de Doctorat de l'Université Pierre et Marie Curie, Paris.

7. Gatignol, R. \& Seppecher, P. (1986): "Modelisation of fluid-fluid interfaces with material properties", J. Mécan. Th. et Appl., Numéro spécial, 225-247.

8. Klimov,A. M. (1963): Zhur. Pricl. Mech. Tekhn. Fiz., 49, $\mathrm{n}^{\circ} 3$.

9. Sivashinsky, G.I., (1975): "Structure of Bunsen flames", J. Chem. Phys., 62, 638-643.

10. Clavin, P. \& Joulin, G. (1983): "Premixed flames in large and high intensity turbulent flow", J. Phys. Lett., 44, $\mathrm{n}^{\circ} 1$, L1-L12.

11. Prud'homme, R., (1988): Fluides hétérogènes et réactifs: écoulements et transferts, Lecture Notes in Physics, $n^{\circ}$ 304, Springer Verlag, Berlin.

12. Delhaye, J.M. (1974): "Jump conditions and entropy sources in two-phase systems", Int. J. Multiphase Flow, 1, 395-409.

13. Scriven, L.E. (1960): "Dynamics of a fluid interface. Equation of motion for Newtonian surface", Chem. Engng. Sci., 12, 98-108. 
14. Slattery, J.C. (1967): "General balance equation for a phase interface", I\&EC Fundamentals, 6, $\mathrm{n}^{\circ} 1$, p. 108.

15. Rocard, Y. (1967): Thermodynamique, Masson et Cie, Paris.

16. Landau, L.D.\& Lifschitz, E.M. (1959): Statistical physics, Pergamon"Press, New-York.

17. Bedeaux, D., Albano, A.M. \& Mazur, P. (1976): "Boundary conditions and non equilibrium thermodynamics", Physica, 82A, 438-462.

18. Napolitano, L. G. (1978): "Thermodynamics and dynamics of surface phase" presented at the XXIX Congress of the International Astronautical Federation, Dubrovnik, Yugoslavia, (preprint IAF-78207).

19. Prosperitti, A. (1979): "Boundary conditions at a liquid-vapor interface”, Meccanica, 14, 34-47.

20. Ghez, R. (1966): "A generalized Gibbsian surface", Surface Science, 4, 125-140.

21. Ghez, R. (1970): "Irreversible thermodynamics of a stationary interface", Surface Science, 20, 326334.

22. Prud'homme, R. (1971): "Equations du bilan de systèmes comprenant des interfaces", Journal de Physique, 32, Colloque $\mathrm{C} 5$, tome b, supplément au $\mathrm{n}^{\circ} 10,62-63$.

23. Ishii, M. (1975): Thermo-fluid dynamic theory of two phase flow, Eyrolles, Paris.

24. Gogosov, V.V., Naletova, VA, Chung Za Bin \& Shapeoshnikova, G.A. (1983): "Conservation laws for the mass, the momentum and energy on a phase interface for true and excess surface parameters", Fluid Dynamics, 6, 923-930.

25. Sanfeld, A. \& Steinchen, A. (1996): "Surface excess momentum balances by i,tegration across the surface of the volume balances", in Dynamics of Multiphase Flows across Interfaces, A. Steinchen (Ed.), Lecture Notes in Physics, $n^{\circ}$ 467, Springer Verlag, Berlin, 28-36.

26. Meinhold-Heerlein (1979): "Surface conditions for the liquid-vapor system, taking in account entropy production caused by mass and energy transport across the interface", Physical Review A, 8, 2574-2585.

27. Gibbs, J. W. (1961): "The scientific papers of J. W. Gibbs", Dover Publ. Inc., New-York, 1, 219-274.

28. Slattery, J.C. (1990): Interfacial transport phenomena, Springer-Verlag, Berlin.

29. Defay, R., Prigogine, I.,Bellemans,A. \& Everett, D. H. (1966): Surface tension and adsorption, Longmans Green, London.

30. De GROOT, S.R. \& MAZUR, P. (1984): Nonequilibrium thermodynamics, North-Holland Pub. Co, Amsterdam.

31. Scriven, L.E. \& Sternling, C.V. (1964): "On cellular convection driven by surface-tension gradients: effects of mean surface tension and surface viscosity", Chem. Engng. Mech., 19, 321340.
32. Palmer, H.J. (1976): "The hydrodynamic stability of rapidly evaporating liquids at reduced pressure", J. Fluid Mech., 75, 487-511.

33. SEFIANE, K., BÉNIELLI, D. \& STEINCHEN, A. (1998): "A new mechanism for pool boiling crisis, recoil instability and contact angle influence", Colloids and Surfaces A: Physicochem. Eng. Aspects, 142, 361-373.

34. Nicolaiev, V.S. \& Beysens, D.A. (1999): "Boiling crisis and non-equilibrium drying transition", Europhys. Lett., 47, 345-351.

35. Pomeau, Y. (2001) "Moving contact line", J. Phys. IV France 11, Pr6-199-212.

36. Jamet, N. (1998): Modélisation des discontinuities dans les écoulements diphasiques compressibles, Thèse de Doctorat de l'Université Pierre et Marie Curie, Paris.

37. Jamet, N., Prud'homme, R. \& Gottesdiener, L. (2001) "Modélisation interfaciale de chocs dans les suspensions", $X V^{\text {ème }}$ Congrès Français de Mécanique, 3-7 septembre 2001.

38. Kurowski, P., Mibah, C. \& Tchourkine, S. (1995): "Gravitational instability of a fictitious front during mixing of miscible fluids", Europhys. Lett., 29, 309314.

39. Zappoli, B., Amiroudine, S. \& Gauthier, S. (1997): "Instabilité gravitationnelle dans un fluide supercritique pur", C. R. Acad. Sci. Paris, 325, Série Ilb, 1-6.

40. Raynal, L. (1997): Instabilité et entrainement à l'interface d'une couche de mélange liquide-gaz, Thèse de Doctorat de l'Université Joseph Fourier, Grenoble.

41. Candel, S.M. \& Poinsot, T. (1990) Flame stretch and the balance equation for the flame area, Combust. Sc. And Technol., 70, 1-5.

42. Lhuillier, D., Morel, C. \& Delhaye J.-M. (2000) Bilan d'aire interfaciale dans un mélange diphasique : approche locale vs approche particulaire, C.R. Acad. Sci. Paris, 328, Série lib, 143-149.

43. El Ganaoui, M.(1997) Modélisation numérique de la convection thermique instationnaire en présence d'un front de solidification déformable, Thèse de I'Université d'Aix-Marseille.

44. Plapp, M. \& Karma, A. (2001) Eutectic colony formation: A phase field model, arXiv:condmat/0112194 v1 11 dec, 1-18.

45. Jamet, D., Lebaigue, O., Coutris, N. \& Delhaye, J.-M. (1997) A numerical description of a liquid-vapor interface based on the second gradient theory, Fluid Mechanics Research, Mars.

46. Jamet, D. \& Petitjeans (2001) A physical justification of a phase-field model for interfaces separating miscible fluids. International Workshop on Miscible Interfaces, ESPCI, Paris, 2-5 July. 
